\title{
BJSM
}

\section{Use of field-based tests to identify risk factors for injury to fast bowlers in cricket}

R J Dennis, C F Finch, A S McIntosh, et al.

Br J Sports Med 2008 42: 477-482 originally published online April 7, 2008 doi: 10.1136/bjsm.2008.046698

Updated information and services can be found at:

http://bjsm.bmj.com/content/42/6/477.full.html

\section{These include:}

References This article cites 36 articles, 10 of which can be accessed free at: http://bjsm.bmj.com/content/42/6/477.full.html\#ref-list-1

Email alerting Receive free email alerts when new articles cite this article. Sign up in the service box at the top right corner of the online article.

Notes

To request permissions go to:

http://group.bmj.com/group/rights-licensing/permissions

To order reprints go to:

http://journals.bmj.com/cgi/reprintform

To subscribe to BMJ go to:

http://journals.bmj.com/cgi/ep 


\title{
Use of field-based tests to identify risk factors for injury to fast bowlers in cricket
}

\author{
R J Dennis, ${ }^{1,2}$ C F Finch, ${ }^{2}$ A S McIntosh, ${ }^{3}$ B C Elliott ${ }^{4}$
}

${ }^{1}$ NSW Injury Risk Management Research Centre, University of NSW, Sydney, NSW, Australia ${ }^{2}$ School of Human Movement and Sport Sciences, University of Ballarat, Ballarat, Victoria, Australia; ${ }^{3}$ School of Safety Science, University of NSW. Sydney, NSW, Australia; ${ }^{4}$ School of Human Movement and Exercise Science, University of Western Australia, Crawley, WA, Australia

Correspondence to: Dr R Dennis, IRMRC, University of NSW, Sydney, NSW, 2052

Australia; rebecca.dennis@ unsw.edu.au

Accepted 26 March 2008

Published Online First

7 April 2008

\section{ABSTRACT}

Objective: To identify risk factors for injury to cricket fast bowlers using field-based tests.

Design: Prospective cohort study.

Setting: High performance Australian cricket.

Participants: Ninety-one male adolescent and adult fast bowlers (aged 12-33 years).

Assessment of risk factors: A field-based preparticipation screening, consisting of musculoskeletal, fitness and anthropometric assessments and analysis of bowling technique was undertaken. Bowlers were prospectively monitored over the 2003-4 season and bowling workload and injuries were recorded. Logistic regression was used to identify injury risk factors.

Main outcome measurement: Repetitive microtrauma injury to the trunk, back or lower limb associated with fast bowling.

Results: Two variables were identified as independent predictors of injury in the multivariate logistic regression analysis. Bowlers with hip internal rotation of $\leqslant 30^{\circ}$ on the leg ipsilateral to the bowling arm were at a significantly reduced risk of injury (OR $0.20,95 \% \mathrm{Cl} 0.06$ to 0.73 ) compared with bowlers with $>40^{\circ}$ of rotation. Bowlers with an ankle dorsiflexion lunge of $12.1-14.0 \mathrm{~cm}$ on the leg contralateral to the bowling arm were at a significantly increased risk (OR 4.03, 95\% $\mathrm{Cl} 1.07$ to 15.21) than bowlers with a lunge of $>14 \mathrm{~cm}$. Bowlers with a lunge of $\leqslant 12 \mathrm{~cm}$ were also at an increased risk, but not significantly so (OR $1.38,95 \% \mathrm{Cl} 0.40$ to 4.84 ).

Conclusions: Biomechanical research is needed to investigate how these two intrinsic risk factors increase injury risk so that appropriate interventions can be developed.

Internationally, surveillance of cricket injuries has consistently identified fast bowlers as the players at greatest risk of injury. ${ }^{1-8}$ Of particular concern is the repetitive microtrauma (overuse injuries) sustained by fast bowlers, such as lumbar stress fractures, as they can prevent participation in cricket for extended periods of time and related impairments may restrict function generally. Such injuries develop gradually and are associated with the cumulative effects of microtrauma to the musculoskeletal system. ${ }^{910}$ Two distinct pathways have been proposed by which cumulative microtrauma leads to symptoms or impairments. In the first, continuous exposure to a pattern of loading and/or other factors simply exacerbates the microtrauma. ${ }^{11}{ }^{12}$ In the second, an otherwise normal load causes failure of the structure weakened by microtrauma. ${ }^{13}$

It has been proposed that fast bowling repetitive microtrauma (hereafter referred to as "injury") is related to a combination of poor technique, poor physical preparation and overuse (in terms of bowling workload). ${ }^{14-16}$ Biomechanical studies of fast bowling techniques have reported bony and soft tissue lower back injuries as being more common with a mixed bowling technique than with a front-on or side-on technique. ${ }^{14} 1517$ Other studies have considered the role of physical characteristics of fast bowlers ${ }^{14} 15$ and bowling workload $^{14}{ }^{19-22}$ in the aetiology of injury.

However, the use of cross-sectional and retrospective study designs has limited the ability of many previous studies to establish cause-effect relationships between putative risk factors and injury. Furthermore, some studies have relied on specialised equipment and facilities to test the bowlers, and the degree to which the testing procedures can be adopted in the cricket "real world" is unclear. This paper presents the results of a prospective cohort study using a field-based screening protocol to concurrently measure bowling workload, bowling technique and physical characteristics as risk factors for injury to adolescent and adult fast bowlers.

\section{METHODS}

\section{Bowler recruitment}

Players were selected from the male Under 13, 15, $17,19,23$ years or state high performance squads in New South Wales and Queensland, Australia for the 2003-4 summer cricket season. Coaches identified all fast bowlers (of which there were usually 7-8) from each squad of 25-30 players. A total of 91 bowlers were recruited, and all bowlers (and a parent/guardian for those aged $<18$ years) provided written consent.

\section{Pre-participation screening protocols and testing procedures}

Bowlers completed a pre-participation screening assessment before the 2003-4 season. This consisted of three major components: a musculoskeletal assessment, a two-dimensional multiple plane analysis of bowling technique and a fitness and anthropometric assessment. As the majority of fast bowling injuries are to the back, trunk and lower limb, ${ }^{12}{ }^{22}$ the identification of potential risk factors for these injuries was the primary focus of the screening protocol. The tests were also chosen for their ease of use in the field environment and because they did not require highly specialised equipment.

\section{Musculoskeletal assessment}

A number of tests measuring flexibility, strength and stability were conducted, with a detailed description of the procedures provided elsewhere. ${ }^{23}$ A summary is provided in table 1. 
Table 1 Summary of pre-participation musculoskeletal assessment of cricket fast bowlers

\begin{tabular}{ll}
\hline Screening test & Purpose of test \\
\hline Knee extension & $\begin{array}{l}\text { To assess hamstring muscle } \\
\text { length in a position of hip flexion }\end{array}$ \\
Modified Thomas test (hip extension) & $\begin{array}{l}\text { To assess flexibility of the hip } \\
\text { flexors }\end{array}$ \\
Modified Thomas test (hip abduction) & $\begin{array}{l}\text { To assess degree of hip } \\
\text { abduction }\end{array}$
\end{tabular}

Hip internal and external rotation

Combined elevation

Prone four point hold

Bridging hold

Ankle dorsiflexion lunge

Calf heel raises

\section{Procedure}

Range of assisted active knee extension measured $\left({ }^{\circ}\right)$ in a supine position with the hip of the testing leg held in $90^{\circ}$ flexion ${ }^{24}$

In a supine position, the contralateral hip is held in maximal flexion with testing leg lowered towards the floor. Femur angle measured $\left({ }^{\circ}\right)$ relative to the horizontal ${ }^{25}$

Same as above. External rotation then added to the contralateral hip to move the anterior superior iliac spine (ASIS) of the left and right side into a parallel alignment. Femur angle measured $\left({ }^{\circ}\right)$ with the centre of the goniometer over the ipsilateral ASIS, with the flexible arm positioned to the opposite ASIS ${ }^{25}$

To assess range of hip rotation in a neutral hip position To assess combined thoracic extension (strength and range of motion), shoulder girdle flexion and scapula retraction

To assess lower abdominal strength and endurance

Prone position, with hips extended and testing knee flexed at $90^{\circ}$. Contralateral knee extended and line of tibia of testing leg measured $\left({ }^{\circ}\right)$ relative to the vertical ${ }^{24}$

Prone position, arms outstretched, with feet, hips, chest and chin in contact with floor. Both arms raised off floor as high as possible without flexing elbows. Measured perpendicular distance $(\mathrm{cm})$ from the base of the metacarpal of the thumb to the floor

Prone position, elbows flexed at $90^{\circ}$. Trunk raised off floor, resting on forearms and toes, holding a neutral lumbopelvic position as long as possible. Measured length of time (s) neutral position held

To assess gluteal strength and endurance

Supine position, both knees flexed at $90^{\circ}$. Hips and pelvis raised off floor to attain a continuous alignment from the shoulder through to the hip and knee. Contralateral foot then raised off floor and, with the foot in a neutral position, knee fully extended without lowering the hips or arching the lower back. Measured length of time (s) this position held

Tape measure fixed along floor. Foot positioned beside tape so that heel line and big toe aligned. To assess range of dorsiflexion at the ankle joint and mobility in the midfoot

Heel held to prevent it from lifting off the floor and subtalar joint manually locked. Lunge forward until knee touches wall. Maximum distance $(\mathrm{cm})$ from great toe to the wall recorded

To assess endurance of the ankle plantar flexor muscles in a weightbearing task
Stand on one foot, rise onto ball of that foot as high as possible, then slowly lower heel while maintaining knee extension. Number of raise/lower cycles recorded
For range of motion tests, a modified goniometer was used. A spirit level was attached to one arm of the goniometer so that the degree of motion relative to the vertical could be determined. Where bilateral tests were conducted, measurements were recorded as the "bowling" and "non-bowling" sides of the body. For example, for right-handed bowlers, tests on the right side were classified as the "bowling" side. This was done so that differences between the dominant and non-dominant sides of the body could be identified.

Two-dimensional multiple plane analysis of bowling technique The protocol incorporated various technical measurements of the fast bowling action based on those used in previous studies (table 2).
Video footage of the bowling action was captured by side-on and overhead digital cameras at 25 frames per second. The sideon camera was perpendicular to the bowling direction on the bowling side of the body (sagittal plane) and the overhead camera was placed directly above the bowling crease (transverse plane), mounted perpendicular to the floor. Both cameras were focused halfway between the popping crease and the bowling crease. Footage was analysed using the Siliconcoach video motion analysis software (Sport and Physical Education Technology Ltd, New Zealand; www.siliconcoach.com).

Bowlers wore tights and their usual training shoes and were instructed to warm up and be ready to bowl at full match pace. The testing facilities enabled the bowler to use their normal full run-up. They were asked to bowl a minimum of four legal

Table 2 Summary of pre-participation analysis of cricket fast bowling technique

\begin{tabular}{|c|c|c|}
\hline Screening test & Purpose of test & Procedure \\
\hline Stride length & Length of bowling delivery stride & $\begin{array}{l}\text { Using side-on footage, distance }(\mathrm{cm}) \text { measured from back of heel of back foot at BFI to back of } \\
\text { heel of front foot at FFI. This stride length was also normalised, being expressed as a percentage } \\
\text { of the standing height of the bowler }\end{array}$ \\
\hline Front knee angle & $\begin{array}{l}\text { Angle of front knee during } \\
\text { delivery stride }\end{array}$ & $\begin{array}{l}\text { Using side-on footage, angle of front knee at FFI measured using the line formed by the medial } \\
\text { malleolus marker, medial femoral epicondyle marker and up the middle of the thigh. Angle also } \\
\text { recorded when front knee was most flexed after FFI and prior to ball release }\end{array}$ \\
\hline Height of ball release & Height of ball release & $\begin{array}{l}\text { Using side-on footage, distance }(\mathrm{cm}) \text { measured from the ground directly under the front foot to } \\
\text { the centre of the ball in the frame of ball release. This height was also normalised, being } \\
\text { expressed as a percentage of the standing height of the bowler }\end{array}$ \\
\hline Ball speed & Ball speed at ball release & $\begin{array}{l}\text { Using side-on footage, ball speed }(\mathrm{km} / \mathrm{h}) \text { calculated from the frame at ball release (the first } \\
\text { frame the ball is not in contact with the hand) to one frame after ball release }\end{array}$ \\
\hline Shoulder angle at BFI & Shoulder alignment at BFI & $\begin{array}{l}\text { Using overhead footage, a line was drawn through the primary alignment of the acromion } \\
\text { process at BFI. This line was continued down the pitch, parallel to the alignment of the pitch, } \\
\text { and the angle }\left({ }^{\circ}\right) \text { of the shoulders relative to the pitch alignment in the direction of bowling was } \\
\text { measured }\end{array}$ \\
\hline Minimum shoulder angle & $\begin{array}{l}\text { Alignment of shoulders in most } \\
\text { side-on position }\end{array}$ & $\begin{array}{l}\text { Using overhead footage, the frame in which the shoulders obtained the most side-on position } \\
\text { between BFI and ball release (usually just before FFI) was identified. The angle }\left({ }^{\circ}\right) \text { of the } \\
\text { shoulders relative to the pitch alignment in the direction of bowling was measured. }\end{array}$ \\
\hline Shoulder counter-rotation & $\begin{array}{l}\text { Rotation of shoulders to a more } \\
\text { side-on position after BFI }\end{array}$ & $\begin{array}{l}\text { This was automatically determined by subtracting the minimum shoulder angle from the } \\
\text { shoulder angle at BFI }\end{array}$ \\
\hline
\end{tabular}

$\mathrm{BFI}$, back foot impact (defined as the point in time when the back foot was in first full contact with the ground during the delivery stride); FFl, front foot impact (defined as the point in time when the front foot was in first full contact with the ground during the delivery stride). 
Table 3 Summary of pre-participation fitness and anthropometric assessment of cricket fast bowlers

\begin{tabular}{|c|c|c|}
\hline Screening test & Purpose of test & Procedure \\
\hline Height & To assess height & Height $(\mathrm{cm})$ recorded using a tape measure fixed to a vertical wall \\
\hline Body mass & To assess body mass & Body mass $(\mathrm{kg})$ recorded using electronic digital scales \\
\hline Skinfolds & To assess percentage body fat & $\begin{array}{l}\text { Skinfolds assessed using Harpenden calipers with all measurements }(\mathrm{mm}) \text { taken on the } \\
\text { right side of the body. Measurements added together to determine sum of seven skinfolds }\end{array}$ \\
\hline Vertical jump & $\begin{array}{l}\text { To assess peak height of a } \\
\text { countermovement vertical jump }\end{array}$ & $\begin{array}{l}\text { Countermovement vertical jump performed. Starting height (maximal reach of the bowling } \\
\text { arm while standing) subtracted from peak jump height to determine height jumped. A } \\
\text { yardstick jumping device was used in Queensland and a wall-mounted board was used in } \\
\text { NSW }\end{array}$ \\
\hline Chest medicine ball throw & $\begin{array}{l}\text { To assess peak distance of a seated } \\
\text { chest throw }\end{array}$ & $\begin{array}{l}\text { Seated position on floor, legs extended, } 3 \mathrm{~kg} \text { medicine ball held against chest, with elbows } \\
\text { bent. Elbows then extended and ball pushed forward. Maximal distance recorded }(\mathrm{cm})\end{array}$ \\
\hline Side-on medicine ball throw & $\begin{array}{l}\text { To assess peak distance of a standing } \\
\text { side-on throw }\end{array}$ & $\begin{array}{l}\text { Feet shoulder width apart facing perpendicular to direction of throw with } 3 \mathrm{~kg} \text { medicine } \\
\text { ball held in both hands directly in front of body. Using a movement similar to a golf swing, } \\
\text { the ball is rotated backwards then forwards to throw the ball. Maximal distance recorded } \\
(\mathrm{cm})\end{array}$ \\
\hline
\end{tabular}

$\mathrm{BFI}$, back foot impact (defined as the point in time when the back foot was in first full contact with the ground during the delivery stride); FFI, front foot impact (defined as the point in time when the front foot was in first full contact with the ground during the delivery stride).

deliveries (front foot no-ball law) over the wicket while being filmed. For the purposes of standardised analysis, the bowler was instructed to attempt to bowl a good line and length. The fastest delivery was selected for analysis.

The following sites were marked using tape and/or a nonpermanent black marker on both sides of the body to allow digitisation in Siliconcoach: acromion process, medial and lateral humeral epicondyle, ulnar and radial styloid, greater trochanter, anterior superior iliac spine, medial and lateral femoral epicondyle, medial and lateral malleolus.

\section{Fitness and anthropometric assessment}

These tests focused on body composition, strength, power and aerobic fitness and were chosen for their ease of use in the field environment because they did not require highly specialised testing equipment (table 3 ).

\section{Bowling workload}

All participants were asked to complete daily bowling log books of the number of training, match and warm-up deliveries bowled each day for the entire 2003-4 season. This diary was submitted weekly and entered into a central database. Unfortunately, despite regular encouragement and the successful use of log books in an earlier study, ${ }^{22}$ the workload data provided by the participants was of poor quality and incomplete. It was therefore excluded from the final analysis.

\section{Injury surveillance}

Injury was defined as a condition that affected availability for team selection in a match; and/or required surgery at any stage of the year; and/or during a match caused a team member to be absent from the field for $>1 \mathrm{~h}$; or caused a bowler to finish bowling due to symptoms before the end of a normal over; or prevented a bowler from being available to bowl during a match. To be eligible for inclusion, injuries must have been to the back, trunk or lower limb, and had an insidious onset associated with bowling. Unless they met any of the listed criteria, injuries that occurred during training or only affected participation in training sessions were not included.
Bowlers were asked to report any condition or injury, even if it was unrelated to cricket, in their log books. A list of the injury concerns reported by the bowlers was prepared two-weekly and given to a sports physiotherapist who contacted each bowler to determine the date, cause, site, nature and mechanism of injury as well as to determine if the injury met the inclusion criteria. Injury diagnosis was coded in a cricket-specific modification of the Orchard Sports Injury Classification System (OSICS). ${ }^{26}$

\section{Statistical analysis}

All pre-participation screening, workload and injury data were entered into a central Microsoft ACCESS database and then imported to SPSS for analysis.

The main outcome measure of interest was injury (yes/no). Continuous pre-participation screening variables were categorised into approximate tertiles to improve the practical interpretation of the results. The reference group was taken to be the group with the highest tertile for a particular variable. No assumption was made as to which group was the preferred or "best" performing category.

To assess the relationship between potential risk factors and injury, logistic regression models were constructed. ${ }^{27}$ Unadjusted logistic regression analyses were used to identify univariate associations between risk factors and injury. Odds ratios (ORs) were calculated relative to the reference category, as well as $95 \%$ confidence intervals (CIs) and p values. As there was a significant difference between the states (New South Wales or Queensland) for some pre-participation screening variables, the state squad from which the bowler was recruited was included as a covariate in all analyses. Variables with a $p$ value $<0.25$ were selected for inclusion in the multivariate model. $\chi^{2}$ tests were conducted to rule out multicolinearity between variables. ${ }^{27}$

A multivariate logistic regression analysis was then undertaken using a backward likelihood ratio procedure. ${ }^{27}$ The stepwise inclusion and exclusion criteria were set at $p<0.10$ and $\mathrm{p}<0.15$, respectively. The ORs and $95 \%$ CIs were calculated after adjustment for state squad and all other variables. Associations with a $p$ value of $<0.10$ were included in the final 
Table 4 Risk factors for trunk, back and lower limb injury to adolescent and adult fast bowlers, adjusted for state squad

\begin{tabular}{|c|c|c|c|c|c|}
\hline \multirow[b]{2}{*}{ Screening test } & \multirow{2}{*}{$\begin{array}{l}\text { N (\% of bowlers in this } \\
\text { category who were injured) }\end{array}$} & \multicolumn{2}{|l|}{ Univariate analysis } & \multicolumn{2}{|l|}{ Multivariate analysis } \\
\hline & & OR $(95 \% \mathrm{Cl})$ & p Value & OR $(95 \% \mathrm{Cl})$ & p Value \\
\hline Hip internal rotation $\left({ }^{\circ}\right)(B)$ & & & 0.233 & & 0.045 \\
\hline $31-40$ & $38(34.2)$ & 0.45 (0.16 to 1.30$)$ & & 0.36 (0.12 to 1.11$)$ & \\
\hline$>40$ & $24(54.2)$ & Ref & & Ref & \\
\hline Ankle dorsiflexion lunge $(\mathrm{cm})(\mathrm{NB})$ & & & 0.114 & & 0.060 \\
\hline$>14.0$ & $20(30.0)$ & Ref & & Ref & \\
\hline Calf heel raises (B) & & & 0.234 & & \\
\hline$\leqslant 15$ & $22(22.7)$ & $0.41(0.10$ to 1.79$)$ & & & \\
\hline $16-25$ & $51(43.1)$ & $1.13(0.35$ to 3.68$)$ & & & \\
\hline$>25$ & $17(35.3)$ & Ref & & & \\
\hline Maximum front knee angle $\left({ }^{\circ}\right)$ & & & 0.193 & & \\
\hline
\end{tabular}

$\mathrm{B}$, bowling side of the body (ipsilateral to the bowling arm); $\mathrm{Cl}$, confidence interval; $\mathrm{NB}$, non-bowling side of the body (contralateral to the bowling arm); OR, odds ratio.

model. ${ }^{27}$ The goodness-of-fit of the final model was determined using the Hosmer-Lemeshow test.

\section{RESULTS}

Of the 91 participating bowlers, 72 (79.1\%) were right-handed bowlers and 19 (20.9\%) were left-handed bowlers. The median age was 17.8 years (range 12.3-33.1). Of these, 53 bowlers $(58.2 \%)$ were adolescent (aged $\leqslant 18$ years) and $38(41.8 \%)$ were adults ( $>18$ years). The age of bowlers at the time of baseline screening was investigated in the univariate analysis but was not associated with injury $(p=0.641)$ and was therefore not included in the multivariate model.

Of the 53 adolescent bowlers, 20 (37.7\%) were injured compared with 17 (44.7\%) of the 38 adult bowlers. The most common injuries were lumbar injuries (other than stress fractures/reactions) $(n=10)$, groin injuries $(n=6)$ and heel and achilles injuries $(n=4)$. Other included injuries were side and abdominal strains and lumbar stress fractures/reactions. Thirty-four bowlers (37.4\%) reported an injury that met the criteria for inclusion in the analyses.

Four measures passed the selection criteria for inclusion in the multivariate model (table 4). Two of these were on the leg ipsilateral to the bowling arm: hip internal rotation and calf heel raises. The other two were on the leg contralateral to the bowling arm: ankle dorsiflexion lunge and maximum front knee angle. $\chi^{2}$ analyses confirmed that the four variables selected for inclusion in the multivariate model were not significantly correlated and therefore all four variables were considered further. The state squad from which the bowler was recruited was also included as a covariate.

The modelling strategy identified only two variables as independent predictors of injury. Reduced hip internal rotation on the leg ipsilateral to the bowling arm (back foot landing leg in the delivery stride) was associated with a significantly decreased risk of injury, and reduced ankle dorsiflexion on the leg contralateral to the bowling arm (front foot landing leg) was associated with a significantly increased risk of injury (table 4). The lunge test was used to measure ankle dorsiflexion and hip internal rotation was measured in a prone position (as described in table 1). The Hosmer-Lemeshow statistic for goodness-of-fit showed that the data fitted the model well $\left(\chi^{2}=0.98\right.$, $\mathrm{p}=0.995)$.

\section{DISCUSSION}

This prospective cohort study of fast bowlers conducted over one summer cricket season measured a broad range of musculoskeletal, fitness, anthropometric and technique variables through a pre-participation screening. Of the 35 measures, only two were identified as independent predictors of injury. Reduced hip internal rotation on the back foot impact leg was associated with a significantly decreased risk of injury, and reduced ankle dorsiflexion on the front foot impact leg was associated with a significantly increased risk of injury.

Several studies have identified decreased ankle dorsiflexion as a risk factor for a range of injuries, including lower extremity injury to Australian footballers, ${ }^{28}$ ankle injury in children, ${ }^{29}$ metatarsal stress fractures in soldiers, ${ }^{30}$ patellar tendon injury in volleyball players, ${ }^{31}$ plantar fasciitis in physiotherapy patients ${ }^{32}$ and patellofemoral pain syndrome in recreational runners. ${ }^{33} \mathrm{~A}$ lack of ankle dorsiflexion on the front foot impact leg could relate to injury to fast bowlers in a number of ways. Tight calf musculature with a lack of ankle dorsiflexion may contribute to higher ground reaction forces at front foot impact as there is less displacement available to attenuate the impact. Compromised function of the calf muscle could increase load on the knee and patellar tendon via the closed kinetic chain. ${ }^{34}$ Alternatively, it may be possible that decreased ankle dorsiflexion results in changes in both tibial and femoral alignment, which have been speculated to cause changes in optimal pelvis and lumbar spine alignment in weight bearing. ${ }^{35}$

Previous studies have suggested that a lack or excessive amount of hip rotation can be a risk factor for injury. One study reported that male soldiers with exertional medial tibial pain had a significantly increased range of hip internal rotation and hip external rotation, but that female soldiers did not. ${ }^{36}$ It has also been proposed that increased hip internal rotation is associated with an increased risk of non-contact knee injury. ${ }^{37}$ The mechanism by which decreased hip internal rotation on the back foot impact leg is related to a decreased risk of injury is not clear, but it may be possible that increased hip internal rotation is an indicator of inadequate gluteus medius control. ${ }^{38}$

Although this study has identified decreased ankle dorsiflexion and increased hip internal rotation as risk factors for injury, only further detailed biomechanical studies will be able to explain how they contribute to the internal loads in the lower 
limb. It would also be of interest to investigate whether the adopted field-based screening measures of ankle dorsiflexion and hip rotation accurately reflect the movement that occurs dynamically at certain stages of the delivery, such as at front and back foot impacts.

It has been stated that injury interventions should focus on modifying the loads applied externally and internally to the body, either by reducing the loads to below relevant injury tolerance criteria or by improving the body's capacity to tolerate certain patterns of loading. ${ }^{39}$ The results of this study suggest that, once a clearer understanding of the potential injury mechanisms is available, it would be worth examining how interventions to improve ankle dorsiflexion range and control of hip internal range of motion could be developed and evaluated for their effectiveness in preventing fast bowling injury.

Previous research has reported a consistent association between the mixed bowling technique and injury. ${ }^{14} 1517$ However, none of the technique measures in this study were independent predictors of injury. This may be due to limitations of using a two-dimensional analysis of bowling technique, with the field-based screening protocols not providing the same level of accuracy afforded by laboratory-based tests. Alternatively, it may be possible that the high performance fast bowlers who participated in this study had already corrected any technique faults prior to the conduct of this study due to their more advanced coaching.

The major strength of this study was the prospective collection of injury data following a comprehensive field-based pre-participation screening. As a cricket physiotherapist consulted with each injured bowler to confirm the symptoms associated with the reported injuries, more accurate injury data was collected than studies relying solely on the bowlers' selfreported recall. Although this study focused on injuries that were attributable to fast bowling, it is possible that the pathogenesis of some of the included injuries is related to other causes, including incomplete recovery from previous injury.

There has been some debate in the literature as to whether all musculoskeletal tissues are subject to unrecovered deformation as a result of repetitive loading. There is evidence to support the role of cumulative microtrauma in the aetiology of injuries to bone, ${ }^{12} 4041$ cartilage, $^{12}$ tendon and ligament, ${ }^{12}{ }^{12}$ but the relationship with muscle strain injuries is not so well understood. Hence, it is acknowledged that the aetiology of the injuries sustained by fast bowlers is complex and that the role of cumulative trauma is not clearly established for all musculoskeletal tissues, particularly muscle.

A potential limitation of this study is the inclusion of a diverse range of musculoskeletal injuries across a range of bowler ages. The risk factors and mechanisms for these injuries will not necessarily be universal, and this may have contributed to only a limited number of significant independent risk factors for injury being identified. ${ }^{28}$ Future research that monitors a larger cohort of bowlers over a longer period is needed to provide sufficient power to identify age-specific risk factors for specific injury types or categories.

Unfortunately, we were not able to include bowling workload data in the multivariate analyses because of the poor capture of this data. This is in contrast to a previous study of adolescent fast bowlers ${ }^{22}$ which successfully used the same bowling workload log books. It would be worth considering other methods for recording bowling workload data that may increase compliance, such as interactive web-based submission or mandatory reporting to squad coaches.
A reliability assessment of all tests included in the preparticipation screening protocol was conducted, with the results relating to the musculoskeletal protocol being described in detail elsewhere. ${ }^{23}$ All musculoskeletal tests had excellent intraobserver reliability, the only exception being the bridging hold test. However, the inter-observer reliability was not as high. All of the tests in the fitness and technique protocols demonstrated excellent intra- and inter-observer reliability. There was a significant difference between the states (New South Wales and Queensland) for some pre-participation screening variables and therefore the state squad from which the bowler was recruited was included as a covariate in all analyses. These differences may be due to differing interpretations of the screening protocols (even though detailed standardised protocols were developed) or poor reliability of some tests used.

With respect to the tests assessing hip internal rotation and ankle dorsiflexion, the ankle dorsiflexion lunge test demonstrated excellent inter-observer reliability (intraclass correlation coefficient $(\mathrm{ICC})=0.96)$ and intra-observer reliability $(\mathrm{ICC}=0.98) .{ }^{23}$ While the intra-observer reliability of the hip internal rotation test was also excellent $(\mathrm{ICC}=0.94)$, the interobserver reliability was very low $(\mathrm{ICC}=0.30)$, which may have influenced these results. It may be possible that some other measures not identified as risk factors were also limited by poor reliability. Alternative field-based tests for some musculoskeletal measures should be evaluated for their intra- and inter-observer reliability and considered for inclusion in future research.

\section{CONCLUSIONS}

This study contributes to the international body of knowledge of risk factors for repetitive microtrauma injury to cricket fast bowlers by identifying two independent risk factors for injury: decreased range of ankle dorsiflexion on the leg contralateral to the bowling arm and increased range of hip internal rotation on the leg ipsilateral to the bowling arm. These findings should be

\section{What is already known on this topic}

- Fast bowlers have been identified as the cricket players at the greatest injury risk, with repetitive microtrauma injuries being of particular concern.

- Bowling technique, physical preparation and bowling workload have been proposed as injury risk factors.

- However, many previous studies are limited by the use of specialised equipment and facilities, and the degree to which the testing procedures can be adopted in the cricket "real world" is unclear.

\section{What this study adds}

- A field-based screening protocol was used to concurrently investigate measures of bowling workload, technique and physical characteristics as injury risk factors for adolescent and adult fast bowlers.

- Increased hip internal rotation and reduced ankle dorsiflexion were identified as independent predictors of trunk, back and lower limb repetitive microtrauma injury.

- This study identifies priority areas for further biomechanical research to investigate how these two intrinsic risk factors contribute to internal loading and increased injury risk. 
the focus of future biomechanical research to investigate how these factors increase injury risk so that appropriate interventions can be developed.

Acknowledgements: The authors acknowledge the valuable contributions of Danny Redrup, Ben Williams, Richard Done, Marc Portus and Andrew Hayen, and thank the participating bowlers and the staff of Cricket NSW and Queensland Cricket including the coaches, physiotherapists, strength and conditioning coaches, performance analysts and other High Performance staff who assisted with this study.

Funding: This project was funded by Cricket Australia. RD was supported by an NHMRC Public Health PhD scholarship during the data collection and analysis phase, and by an NHMRC Population Health Capacity Building Grant in Injury Prevention,

Trauma and Rehabilitation during the reporting and publication phase. CF was supported by an NHMRC Principal Research Fellowship.

Competing interests: None.

Ethics approval: The project was approved by the University of New South Wales Human Research Ethics Committee.

\section{REFERENCES}

1. Orchard J, James T, Alcott $\mathrm{E}$, et al. Injuries in Australian cricket at first class level 1995/1996 to 2000/2001. Br J Sports Med 2002;36:270-4

2. Orchard JW, James T, Portus MR. Injuries to elite male cricketers in Australia over a 10-year period. J Sci Med Sport 2006;9:459-67.

3. Gregory PL, Batt ME, Wallace WA. Comparing injuries of spin bowling with fast bowling in young cricketers. Clin J Sport Med 2002;12:107-12.

4. Stretch RA. The incidence and nature of injuries in first-league and provincial cricketers. S Afr Med J 1993;83:339-42.

5. Stretch RA. The seasonal incidence and nature of injuries in schoolboy cricketers. S Afr Med J 1995;85:1182-4.

6. Stretch RA. Epidemiology of cricket injuries. Int J Sports Med 2001;2:1-7.

7. Stretch RA. Incidence and nature of epidemiological injuries to elite South African cricket players. S Afr Med J 2001;91:336-9.

8. Stretch RA. Cricket injuries: a longitudinal study of the nature of injuries to South African cricketers. Br J Sports Med 2003;37:250-3.

9. Elliott B. Overuse injuries in sport: a biomechanical approach. Safety Science Monitor 1999;3:1-6.

10. Kumar S. Theories of musculoskeletal injury causation. Ergonomics 2001;44:17-47.

11. Meeuwisse WH. Assessing causation in sport injury: a multifactorial model. Clin J Sport Med 1994;4:166-70.

12. Whiting W, Zernicke R. Biomechanics of musculoskeletal injury. Lower Mitcham, Australia: Human Kinetics, 1998.

13. Burgess-Limerick R, Egeskov R. Risk factor identification - the role of ergonomics. In: McClure R, Stevenson M, McEvoy S, eds. The scientific basis of injury prevention and control. Melbourne, Australia: IP Communications 2004:154-68.

14. Foster D, John D, Elliott B, et al. Back injuries to fast bowlers in cricket: a prospective study. Br J Sports Med 1989;23:150-4.

15. Elliott BC, Hardcastle PH, Burnett AF, et al. The influence of fast bowling and physical factors on radiologic features in high performance young fast bowlers. Sports Medicine, Training and Rehabilitation 1992;3:113-30.

16. Elliott B, Foster D, John D. The biomechanics of side-on and front-on fast bowling in cricket. Third Report on the National Sports Research Program: July 1988 to June 1990 Nedlands, Australia: University of Western Australia, 1990.

17. Portus M, Mason BR, Elliott BC, et al. Technique factors related to ball release speed and trunk injuries in high performance cricket fast bowlers. Sports Biomech 2004;3:263-84.
18. Engstrom CM, Walker DG. Pars interarticularis stress lesions in the lumbar spine of cricket fast bowlers. Med Sci Sports Exerc 2007;39:28-33.

19. Dennis R, Farhart P, Clements $M$, et al. The relationship between fast bowling workload and injury in first-class cricketers: a pilot study. J Sci Med Sport 2004; 7:232-6.

20. Gregory PL, Batt ME, Wallace WA. Is risk of fast bowling injury in cricketers greatest in those who bowl most? A cohort of young English fast bowlers. Br J Sports Med 2004;38:125-8.

21. Dennis R, Farhart P, Goumas C, et al. Bowling workload and the risk of injury in elite cricket fast bowlers. J Sci Med Sport 2003;6:359-67.

22. Dennis RJ, Finch CF, Farhart PJ. Is bowling workload a risk factor for injury to Australian junior cricket fast bowlers? Br J Sports Med 2005;39:843-6.

23. Dennis RJ, Finch CF, Elliott BC, et al. The reliability of musculoskeletal screening tests used in cricket. Phys Ther Sport 2008;9:25-33.

24. Harvey D. Screening test protocols. Pre-participation screening of athletes: a program developed by the Australian Institute of Sport, Olympic Athlete Program and the Australian Sports Injury Prevention Taskforce. Canberra, Australia: Australian Sports Commission, 1998.

25. Harvey D. Assessment of the flexibility of elite athletes using the modified Thomas test. Br J Sports Med 1998;32:68-70.

26. Orchard J. Orchard Sports Injury Classification System (OSICS): Version 8.2. 2003 [cited 1 May 2005]. http://www.injuryupdate.com.au/research/OSICS.htm.

27. Dupont WD. Statistical modeling for biomedical researchers: a simple introduction to the analysis of complex data. Melbourne, Australia: Cambridge University Press, 2002.

28. Gabbe BJ, Finch CF, Wajswelner $\mathrm{H}$, et al. Predictors of lower extremity injuries at the community level of Australian football. Clin J Sport Med 2004;14:56-63.

29. Tabrizi P, Mclntyre WM, Quesnel MB, et al. Limited dorsiflexion predisposes to injuries of the ankle in children. J Bone Joint Surg Br 2000;82:1103-6.

30. Hughes LY. Biomechanical analysis of the foot and ankle for predisposition to developing stress fractures. J Orthop Sports Phys Ther 1985; 7:96-101.

31. Malliaras $\mathbf{P}$, Cook JL, Kent P. Reduced ankle dorsiflexion range may increase the risk of patellar tendon injury among volleyball players. J Sci Med Sport 2006;9:304-9.

32. Riddle DL, Pulisic M, Pidcoe P, et al. Risk factors for plantar fasciitis: a matched case-control study. J Bone Joint Surg Am 2003;85:872-7.

33. Lun V, Meeuwisse WH, Stergiou P, et al. Relation between running injury and static lower limb alignment in recreational runners. Br J Sports Med 2004;38:576-80.

34. Cook JL, Khan KM, Purdam CR. Conservative treatment of patellar tendinopathy. Phys Ther Sport 2001;2:54-65.

35. Powers CM. The influence of altered lower-extremity kinematics on patellofemoral joint dysfunction: a theoretical perspective. J Orthop Sports Phys Ther 2003;33:639-46.

36. Burne SG, Khan KM, Boudville PB, et al. Risk factors associated with exertional medial tibial pain: a 12 month prospective clinical study. Br J Sports Med 2004;38:441-5.

37. Pollard CD, Sigward SM, Ota S, et al. The influence of in-season injury prevention training on lower-extremity kinematics during landing in female soccer players. Clin J Sport Med 2006;16:223-7.

38. Nyland J, Kuzemchek S, Parks M, et al. Femoral anteversion influences vastus medialis and gluteus medius EMG amplitude: composite hip abductor EMG amplitude ratios during isometric combined hip abduction-external rotation. J Electromyogr Kinesiol 2004;14:255-61.

39. McIntosh AS. Risk compensation, motivation, injuries, and biomechanics in competitive sport. Br J Sports Med 2005;39:2-3.

40. Bennell K, Matheson G, Meeuwisse W, et al. Risk factors for stress fractures. Sports Med 1999;28:91-122.

41. Brukner P. Sports medicine. Overuse injuries. Part I: Bone. Australian Family Physician 1996;25:545-9.

42. Maganaris CN, Narici MV, Almekinders LC, et al. Biomechanics and pathophysiology of overuse tendon injuries: Ideas on insertional tendinopathy. Sports Med 2004;34:1005-17. 